\title{
Bulk Density Adjustment of Resin-Based Equivalent Material for Geomechanical Model Test
}

\author{
Pengxian Fan, ${ }^{1,2}$ Haozhe Xing, ${ }^{1}$ Linjian Ma, ${ }^{1}$ Kaifeng Jiang, ${ }^{1}$ Mingyang Wang, \\ Zechen Yan, ${ }^{1}$ and Xiang Fang ${ }^{3}$ \\ ${ }^{1}$ State Key Laboratory of Disaster Prevention \& Mitigation of Explosion \& Impact, PLA University of Science and Technology, \\ Nanjing 210007, China \\ ${ }^{2}$ State Key Laboratory of Coal Resources and Safe Mining, China University of Mining and Technology, Xuzhou 221116, China \\ ${ }^{3}$ College of Field Engineering, PLA University of Science and Technology, Nanjing, Jiangsu 210007, China
}

Correspondence should be addressed to Mingyang Wang; wmyrf@163.com

Received 28 May 2015; Accepted 10 September 2015

Academic Editor: Carlo Santulli

Copyright (C) 2015 Pengxian Fan et al. This is an open access article distributed under the Creative Commons Attribution License, which permits unrestricted use, distribution, and reproduction in any medium, provided the original work is properly cited.

\begin{abstract}
An equivalent material is of significance to the simulation of prototype rock in geomechanical model test. Researchers attempt to ensure that the bulk density of equivalent material is equal to that of prototype rock. In this work, barite sand was used to increase the bulk density of a resin-based equivalent material. The variation law of the bulk density was revealed in the simulation of a prototype rock of a different bulk density. Over 300 specimens were made for uniaxial compression test. Test results indicated that the substitution of quartz sand by barite sand had no apparent influence on the uniaxial compressive strength and elastic modulus of the specimens but can increase the bulk density, according to the proportional coarse aggregate content. An ideal linearity was found in the relationship between the barite sand substitution ratio and the bulk density. The relationship between the bulk density and the usage of coarse aggregate and barite sand was also presented. The test results provided an insight into the bulk density adjustment of resin-based equivalent materials.
\end{abstract}

\section{Introduction}

Geomechanical model test is one of the most commonly used approaches in geotechnical engineering research since it was first proposed in the early decades of the 20th century. Generally, the model is built by equivalent material (similar or analogous material) with a smaller size, whose physical parameters are determined according to scaling criteria. The models attempt to simulate, to different degrees, the actual behaviour of the foundation or surrounding rock mass, taking account of actual working conditions, the stress path, actual material behaviour, and the interaction between the structure and contiguous rock mass.

Along with the increased exploration and utilisation of underground spaces for hydraulic power and engineering operations in China, model tests simulating excavations in rock masses, or structures on rock foundations, have been studied widely. The literature reports correlational research and provides beneficial insight into scaling criteria [1], equivalent materials [2], experimental apparatus [3-5], model building technologies [6], and so on. In the meantime, many model tests have been carried out in the field of hydropower engineering, tunnel engineering, mining engineering, and so forth. Zhu et al. conducted a model test of an underground cavern group in 3D stress state at great depth by a resin-based equivalent material, in which cracking and failure of the surrounding rock masses at various overburden depths were monitored [7]. Liu et al. and Chen et al. modelled the high arch dam by equivalent material blocks and investigated the stability of foundation $[8,9]$. The model built by equivalent material also is used to investigate the performance of the surrounding rocks of tunnels and mining openings [10, 11]. All model tests need an appropriate equivalent material to simulate the prototype rock. The similarity between the equivalent material and prototype rock is crucial to the simulation of excavation or structural response. Therefore, 
the development of equivalent materials with appropriate properties is important when seeking reliability in model test results.

The study of the development of equivalent materials dates back to the 1960s: Fumagalli [12] developed the early stage equivalent material, which is composed of gypsum, lead oxide, and bentonite. In the following decades, Glushikhin et al. [13] developed a series of materials for model making, including a sand-urea material, a sand-epoxy material, cement mortar, cement-gypsum mortar, and sand-polymer mixtures; they investigated the short- and long-term deformational properties as well as the dynamic properties thereof. Nevertheless, these early materials generally have some disadvantages, such as their costly, potential toxicity, low bulk density, or inconvenience when used to build larger model.

According to the scaling criterion, the scale factors for stress, length, and bulk density of a material have a determinate relationship:

$$
\frac{\alpha_{\sigma}}{\alpha_{L} \alpha_{\gamma}}=1
$$

Given the scale factor for bulk densities is unity, the relationship can be transformed to

$$
\alpha_{\sigma}=\alpha_{L}
$$

This simplification facilitates model testing and data analysis. To simplify the relationship, people tend to use materials with a higher density (or bulk density) when developing equivalent materials. In recent years, more equivalent materials, with better applicability, have been developed. Li et al. [14] developed an equivalent material (called NIOS), which is composed of gypsum, $\mathrm{Fe}_{3} \mathrm{O}_{4}$ powder, and river sand. The bulk density can reach $25 \mathrm{kN} / \mathrm{m}^{3}$ to $30 \mathrm{kN} / \mathrm{m}^{3}$ : this covers the range of prototype rocks expected in geomechanics. Wang et al. [15] and Zhang et al. [16] developed an equivalent material (called IBSCM), which is composed of iron powder, barites powder, and quartz sand and is cemented by a solution of alcohol and resin. Ren et al. [17] conducted physical simulation testing to investigate the creep behaviour and failure mechanism of the wall rock around a goaf, as well as the deformation of the ground surface. The equivalent material for rock used in that model test consists of barite powder, iron powder, glycerol, and water. Zhu et al. [18] reported a physical model test of a complex excavation under high in situ stresses. A new type of modelling material was developed in their work, which comprises iron, barite, and quartz powders which were bonded with a resin alcohol solution.

Recent trends aimed at ensuring that the scale factor for bulk densities was equal to unity have encouraged increasing application of materials with large densities, such as $\mathrm{Fe}_{3} \mathrm{O}_{4}$ powder, barite powder, or/and iron powder, which make the adjustment of the mechanical and deformation properties of the equivalent material more complicated. However, previous studies have not provided us with an effective solution to this problem. Most of them solve the problem relying on trial and error, which is time consuming and labour intensive.

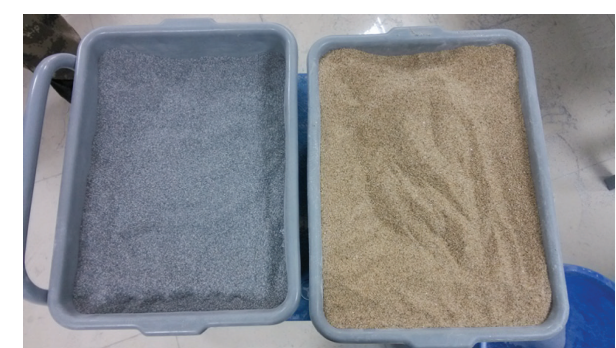

FIGURE 1: Raw material: barite sand and quartz sand.

In this research, we attempted to find a simple method of adjusting the bulk density of the equivalent material, without affecting its key mechanical properties. The equivalent material comprised barite sand, quartz sand, and barite powder and was cemented by a resin alcohol solution. The barite sand and quartz sand had the same grain size and appearance but very different bulk densities. By substituting barite sand for quartz sand, the bulk density of the equivalent material increased significantly, while its mechanical properties remained constant. Experiments were conducted to verify this concept and reveal the relationship between barite sand substitution ratio and the bulk density of the equivalent material. The results showed that the mechanical properties of the equivalent material were not influenced by the substitution ratio of barite sand, and the bulk density increased linearly with increasing barite sand content.

\section{Experimental Method}

\subsection{Preparation of the Resin-Based Equivalent Material}

2.1.1. Raw Materials. The equivalent material used in these experiments was composed of coarse aggregate, fine aggregate, and cementitious material.

The coarse aggregate comprised barite sand and quartz sand (Figure 1). The coarse aggregate was made by crushing the rock, or mineral, into sand. The grain sizes were confined to the range from $0.6 \mathrm{~mm}$ to $1.18 \mathrm{~mm}$. The fine aggregate comprised barite powder only and was made from barite ore by grinding. The fineness was consistent with a material retained between the 300 to 400 meshes. High-quality natural resin, dissolved in $95 \%$ medical alcohol, was used as the blender in this preparation process. When the specimens had been formed by compression and the alcohol volatilised, the resin acted as a cementitious material.

For larger model tests, the cost should be considered. The raw materials used in the preparation of the equivalent material in this research cost $\$ 100$ (USD)/ton for the highquality barite ore. When barite ore was processed into sand and powder, the cost increased to approximately $\$ 200 /$ ton to $\$ 300 /$ ton. The price of the quartz sand was about $\$ 50 /$ ton. Medical alcohol and resin were relatively expensive, but their usage accounts for $5 \%$ to $7 \%$ of the overall mass. The overall cost of the equivalent material was about $\$ 200 /$ ton to $\$ 300 /$ ton, depending on the mix proportions. According to the true $3 \mathrm{D}$ geomechanical model test system in PLA University of Science and Technology (Figure 2), which can 
TABLE 1: Bulk density of raw material $\left(\mathrm{g} / \mathrm{cm}^{3}\right)$.

\begin{tabular}{lcccc}
\hline $\begin{array}{l}\text { Barite sand } \\
\text { (tap density) }\end{array}$ & $\begin{array}{c}\text { Quartz sand } \\
\text { (tap density) }\end{array}$ & $\begin{array}{c}\text { Barite powder } \\
\text { (tap density) }\end{array}$ & $\begin{array}{c}\text { Resin } \\
\text { (granule density) }\end{array}$ & $\begin{array}{c}\text { Barite sand } \\
\text { (tap density) }\end{array}$ \\
\hline 2.032 & 1.458 & 1.656 & 1.074 & 2.032 \\
\hline
\end{tabular}

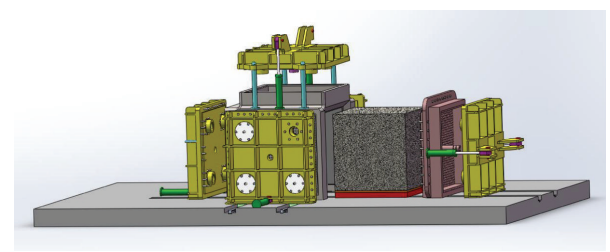

Figure 2: The schematic diagram of the model test system and underground model.

load static and impact loading through the boundaries, the size of a typical model of the surrounding rocks of underground excavation is $1.3 \mathrm{~m} \times 1.3 \mathrm{~m} \times 1.3 \mathrm{~m}$. The material cost of a typical model, weighing about 5 tons, was approximately $\$ 1,500$, which was significantly lower than the loading system and measurement system themselves. Furthermore, most of the material was recyclable. The recycling method will be discussed in other papers.

The bulk densities of the raw materials are listed in Table 1.

2.1.2. Specimen Preparation Procedure. The method of preparation of the specimens was as follows:

(i) Dry the aggregate, including barite sand, quartz sand, and barite powder.

(ii) Weigh the raw material and batch in the desired proportions.

(iii) Blend the aggregate and ensure a homogeneous mix.

(iv) Dissolve the resin in alcohol.

(v) Blend the mixture again, and gradually add the solution from (iv) (above).

(vi) Put the mixture into a mould and compact it under a pressure of 2.0 $\mathrm{MPa}$.

(vii) Demould the specimens and air-cure them.

(viii) Conduct tests when the mass of a specimen has stabilized (the curing period usually takes three to five days, according to ambient conditions).

To ensure that the specimens have identical curing conditions, all specimens were prepared simultaneously and cured together.

\subsection{Design of Experiments}

2.2.1. Experimental Objective. As mentioned, the tests had two main objectives: firstly, to verify that the substitution of quartz sand with barite sand had no apparent influence on the key mechanical properties of the equivalent material (uniaxial compressive strength (UCS) and elastic modulus were chosen as indices thereof here) and secondly, to reveal

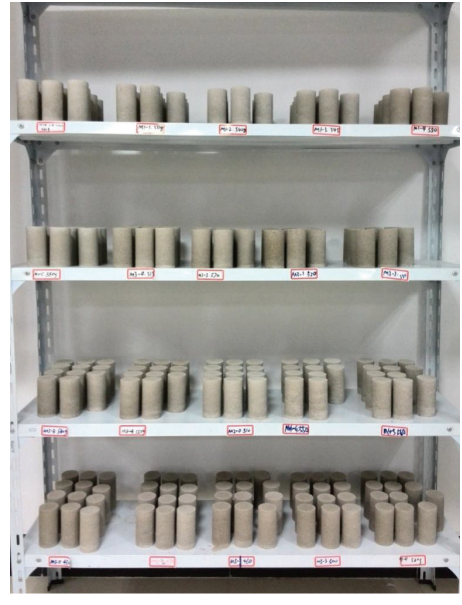

FIgURE 3: Samples curing in air.

the nature of the density change for different proportions of coarse aggregate and substitution ratios of barite sand.

2.2.2. Experiment Design. According to the mix design for this resin-based equivalent material, the specimens were divided into four groups in terms of coarse aggregate proportion: each group had six sets with different barite sand substitution ratios. Each set had no fewer than 10 specimens. The coarse aggregate proportion ranged from $20 \%$ to $50 \%$ in each group, increasing in increments of $10 \%$. The barite sand substitution ratio ranged from $0 \%$ to $100 \%$, increasing in increments of $20 \%$.

The groups were labelled M1, M2, M3, and M4: the sets were numbered from 0 to 5 . The design mix proportions are listed in Tables 2 and 3.

All the specimens were cylindrical and measured $\Phi 50 \mathrm{~mm} \times 100 \mathrm{~mm}$ : the diameters and heights of all specimens were governed by the moulds used and were measured before mechanical testing. The relative errors in the diameter and height values were less than $1 \%$ and $3 \%$, respectively.

More than 300 specimens were tested. Figure 3 shows typical prepared specimens curing in air. The alcohol evaporated and the strength developed gradually. We weighed the specimens on the third day and on later days. The uniaxial compressive strength test was carried out when the loss of specimen mass over two adjacent days was less than $0.1 \%$. Higher temperatures and good ventilation conditions could shorten the curing period.

\section{Results}

The uniaxial compression tests were undertaken in a press machine SANS CDT1504 (MTS, China). The test specimens 
TABLE 2: Design mix proportions (groups).

\begin{tabular}{lcccc}
\hline & $\begin{array}{c}\text { Coarse aggregate } \\
\text { Barite sand and quartz sand }\end{array}$ & $\begin{array}{c}\text { Fine aggregate } \\
\text { Barite powder }\end{array}$ & Resin & 95\% alcohol \\
\hline M1 & $20 \%$ & $80 \%$ & $1 \%$ & $7 \%$ \\
M2 & $30 \%$ & $70 \%$ & $1 \%$ & $5 \%$ \\
M3 & $40 \%$ & $60 \%$ & $1 \%$ & $5 \%$ \\
M4 & $50 \%$ & $50 \%$ & $1 \%$ & $4 \%$ \\
\hline
\end{tabular}

Remarks: the mass of resin was discounted in the denominator when calculating the proportions. In other words, the denominator is the mass of aggregate only. The proportion of alcohol was determined by preexperiments seeking the optimum moisture content for preparation and was also discounted in the denominator.

TABLE 3: Design mix proportions (sets).

\begin{tabular}{lcc}
\hline & \multicolumn{2}{c}{ Coarse aggregate } \\
& Barite sand & Quartz sand \\
\hline $\mathrm{M} x-0$ & $0 \%$ & $100 \%$ \\
$\mathrm{M} x-1$ & $20 \%$ & $80 \%$ \\
$\mathrm{M} x-2$ & $40 \%$ & $60 \%$ \\
$\mathrm{M} x-3$ & $60 \%$ & $40 \%$ \\
$\mathrm{M} x-4$ & $80 \%$ & $20 \%$ \\
$\mathrm{M} x-5$ & $100 \%$ & $0 \%$ \\
\hline
\end{tabular}

Remark: the character $x$ represents one of the Arabic numerals from 0 to 5 .

were placed on the compression plate and loaded monotonically to failure. The load-displacement curves were recorded for postprocessing and analysis. The stress on, and nominal strain of, the tested specimens was determined as follows:

$$
\begin{aligned}
& \sigma=\frac{P}{S}=\frac{4 P}{\pi D^{2}}, \\
& \varepsilon=\frac{\delta}{H} .
\end{aligned}
$$

The experimental results provided values for the bulk density, uniaxial compressive strength, and elastic modulus of the equivalent materials with their different mix proportions. For ease of comparison, the UCS and elastic modulus data from different groups were plotted.

\subsection{Results of Mechanical Property Testing}

3.1.1. UCS Results. Since the machine provided the peak load, the UCS of each specimen was determined by using the following equation:

$$
\sigma_{\mathrm{ucs}}=\frac{P_{\max }}{S}=\frac{4 P_{\max }}{\pi D^{2}} .
$$

The UCS results are shown in Figure 4. The UCS of specimens from groups M1, M2, and M3 remained the same as the proportion of barite sand was increased. This proved that the proportion of barite sand had little influence on the strength of the specimens. The maximum relative deviation was $9.04 \%$ from the groups mentioned above. In group M4, the average UCS of the first five sets had a maximum relative deviation of $9.91 \%$. However, the average UCS of the sixth sample set, in which the proportion of barite sand was $100 \%$, was $32.31 \%$ greater compared to the average UCS of the first five sample sets.

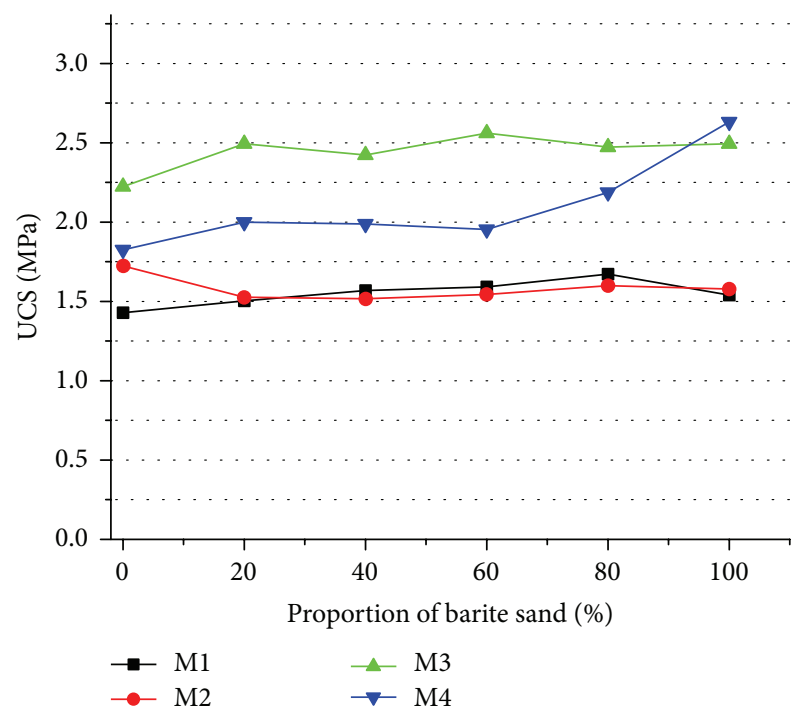

FIGURE 4: UCS versus the proportion of barite sand.

Generally speaking, the influence of the barite sand substitution ratio on the strength of the equivalent material was negligible in most cases, except in the set with the larger barite sand substitution ratio and a higher coarse aggregate content.

The UCS results and relative deviations from the mean are listed in Table 4: in most cases the changes in barite sand content had no systematic effect on the UCS of the specimens, except for set plotted in the bottom right-hand corner.

3.1.2. Elastic Modulus. The elastic modulus of specimen was given by

$$
E=\frac{\sigma_{2}-\sigma_{1}}{\varepsilon_{2}-\varepsilon_{1}}
$$

where $\sigma_{1}$ and $\sigma_{2}$ are the stresses at the start and end of the linear elastic deformation stage, respectively; $\varepsilon_{1}$ and $\varepsilon_{2}$ are the corresponding strains.

In this research, the linear deformation stage was determined by the test program (SANS-Power test D00C). All of the automatically picked results were checked by the authors. If the linear section deviated from a reasonable interval, the result was adjusted manually.

The elastic modulus data are shown in Figure 5: the elastic moduli of samples from groups M1, M2, and M3 remained practically constant, as did their UCS. The maximum relative 
TABLE 4: UCS data.

\begin{tabular}{lcccccccc}
\hline $\begin{array}{l}\text { Barite sand } \\
\text { substitution ratio }\end{array}$ & UCS & $\begin{array}{c}\text { M1 } \\
\text { Relative deviation }\end{array}$ & UCS & $\begin{array}{c}\text { M2 } \\
\text { Relative deviation }\end{array}$ & UCS & $\begin{array}{c}\text { M3 } \\
\text { Relative deviation }\end{array}$ & $\begin{array}{c}\text { UCS } \\
\text { Relative deviation }\end{array}$ \\
\hline 0 & 1.428 & $-7.84 \%$ & 1.723 & $8.98 \%$ & 2.223 & $-9.04 \%$ & 1.824 & $-13.03 \%$ \\
20 & 1.503 & $-3.04 \%$ & 1.527 & $-3.43 \%$ & 2.494 & $2.06 \%$ & 1.999 & $-4.68 \%$ \\
40 & 1.569 & $1.23 \%$ & 1.517 & $-4.08 \%$ & 2.422 & -0.885 & 1.987 & $-5.25 \%$ \\
60 & 1.591 & $2.64 \%$ & 1.544 & $-2.37 \%$ & 2.560 & 4.745 & 1.953 & $-6.86 \%$ \\
80 & 1.670 & $7.77 \%$ & 1.600 & $1.21 \%$ & 2.473 & $1.17 \%$ & 2.187 & $4.31 \%$ \\
100 & 1.540 & $-0.62 \%$ & 1.578 & $-0.18 \%$ & 2.493 & 2.015 & 2.633 & $25.56 \%$ \\
\hline
\end{tabular}

TABLE 5: Elastic modulus data.

\begin{tabular}{lcccccccc}
\hline $\begin{array}{l}\text { Barite sand } \\
\text { substitution ratio }\end{array}$ & $E$ & $\begin{array}{c}\text { M1 } \\
\text { Relative deviation }\end{array}$ & $E$ & $\begin{array}{c}\text { M2 } \\
\text { Relative deviation }\end{array}$ & $E$ & Relative deviation & $E$ & $\begin{array}{c}\text { M4 } \\
\text { Relative deviation }\end{array}$ \\
\hline 0 & 598.7 & -0.18 & 549.9 & 0.12 & 759.4 & -2.22 & 617.7 & -4.98 \\
20 & 568.3 & -5.25 & 562.7 & 2.44 & 792.9 & 2.09 & 609.6 & -6.22 \\
40 & 579.4 & -3.40 & 542.5 & -1.24 & 772.7 & -0.51 & 609.7 & -6.20 \\
60 & 618.5 & 3.12 & 561.5 & 2.22 & 786.3 & 1.24 & 636.5 & -2.08 \\
80 & 631.4 & 5.26 & 566.2 & 3.08 & 767.0 & -1.24 & 724.1 & 11.39 \\
100 & 602.6 & 0.46 & 512.9 & -6.62 & 781.7 & 0.64 & 702.7 & 8.10 \\
\hline
\end{tabular}

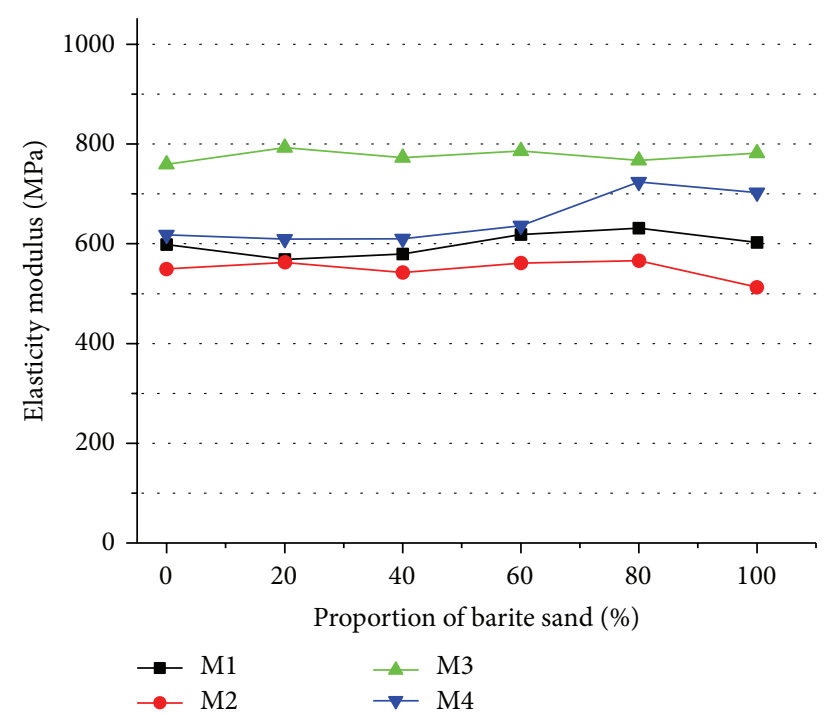

FIGURE 5: Elastic modulus versus the proportion of barite sand.

deviation was $6.62 \%$ in the first three groups. The average elastic modulus of the last two sets in group M4 was also slightly higher than that of the first four sets.

The results followed a similar trend to the UCS data; that is, in most cases the barite sand substitution ratio had little influence on the elastic modulus of the specimens, except in the case of larger barite sand substitution ratios and higher coarse aggregate contents. The elastic modulus data are summarised in Table 5.

Comparing Tables 4 and 5, it was found that although the trend was the same, the maximum relative deviations in elastic modulus were lower than those in UCS across all four groups.

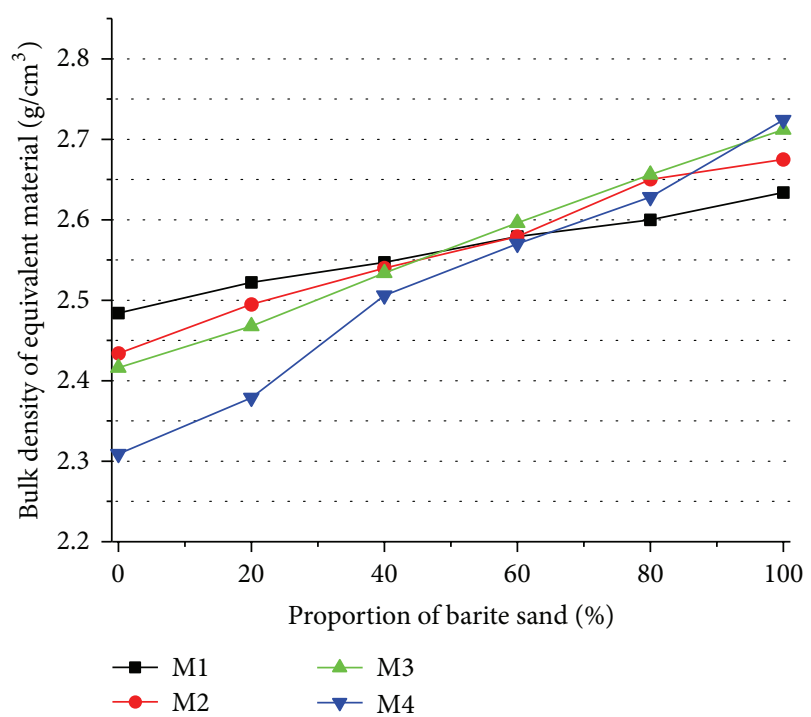

FIgURE 6: Bulk density of the equivalent material versus the proportion of barite sand.

3.2. Bulk Density. The bulk density of each specimen was given by

$$
\rho=\frac{m}{V}=\frac{4 m}{\pi D^{2} H} .
$$

All specimens were weighed and measured. The bulk densities are shown in Figure 6. Each point plotted in Figure 6 represented the average bulk density of more than 10 specimens with identical mix proportions.

From Figure 6, it was seen that the bulk density of the equivalent material increased as the barite sand substitution ratio increased across all four groups. When the proportion 


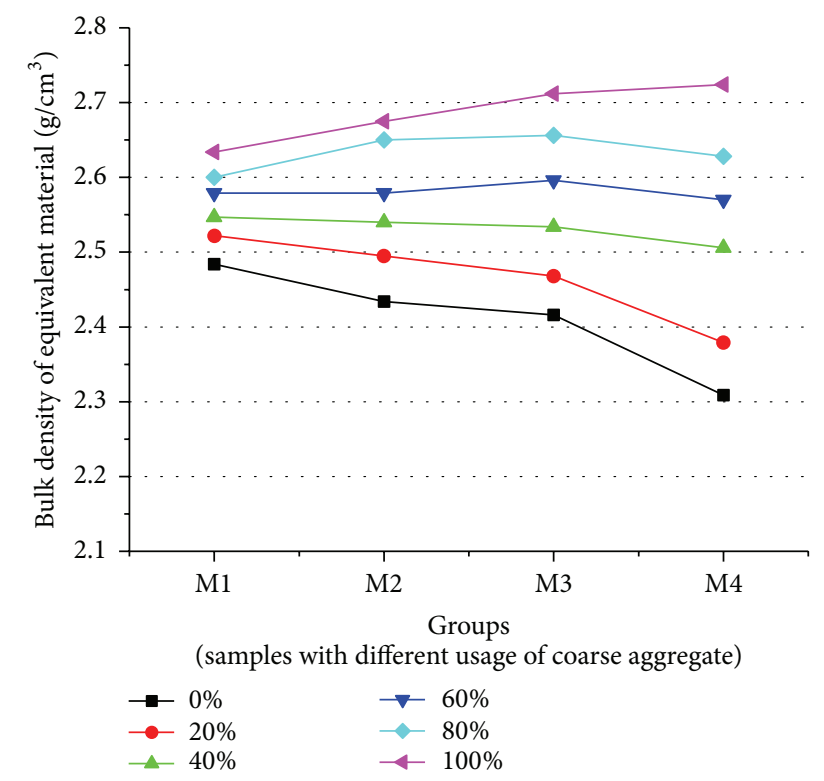

FIGURE 7: Bulk density of the equivalent material versus coarse aggregate content.

of barite sand increased from zero to $100 \%$, the bulk density of samples from group M1 increased from $2.484 \mathrm{~g} / \mathrm{cm}^{3}$ to $2.634 \mathrm{~g} / \mathrm{cm}^{3}$ (an increase of $6.0 \%$ ). For groups M2 to M4, the rates of increase in bulk density were $9.9 \%, 12.3 \%$, and $18.0 \%$, respectively. The more coarse aggregate that was used, the greater the rate of increase in bulk density. The relationship between barite sand substitution ratio and the bulk density of the equivalent material was quasi-linear. For specimens from groups M1 and M3, the linearity was good. The results imply that we can determine the bulk density of equivalent material by linear interpolation, which will facilitate the adjustment of bulk density greatly.

Figure 6 also shows that when the coarse aggregate was composed of quartz sand alone, the bulk density of the equivalent material decreased with increasing coarse aggregate content: when the coarse aggregate was composed of barite sand alone, this trend was reversed. The changes in bulk density were more complicated. It seems that the variation trend relates to the relative density of the raw materials.

To further reveal the trend, curves of bulk density versus the coarse aggregate content are shown in Figure 7 where the following occurred: (1) when the barite sand content was low (less than 40\%), the bulk density decreased with increasing coarse aggregate content; (2) when the barite sand content was $100 \%$, the bulk density increased with increasing coarse aggregate content; and (3) when the barite sand content was between $60 \%$ and $80 \%$, the bulk density first increased and then decreased with increasing coarse aggregate content.

Figure 7 also provides us information about the bulk density of the equivalent material, at different mix proportions, over a broader scope: the preferred bulk density could be chosen by selecting from tested points or by linear interpolation; then, the mechanical properties could be adjusted by varying the added dose of cementing agent or other additives.

\section{Discussion}

4.1. Changes in Bulk Density. If it was assumed that the porosity of material was known and that it remained the same when the mix proportions were identical, then

$$
n=\frac{V_{a}}{V}=\frac{V_{a}}{V_{s}+V_{a}}
$$

in which the subscript $a$ denotes air and subscript $s$ denotes solid.

Combining (6) and (7) gives

$$
\rho=\frac{(1-n) m}{V_{s}} .
$$

The solid volume contained four parts: barite sand, quartz sand, barite powder, and resin, which were described by subscripts $b, q, p$, and $r$, respectively:

$$
V_{s}=V_{b}+V_{q}+V_{p}+V_{r} .
$$

Then

$$
\begin{aligned}
\rho & =\frac{(1-n) m}{V_{b}+V_{q}+V_{p}+V_{r}} \\
& =\frac{(1-n) m}{m_{b} / \rho_{b}+m_{q} / \rho_{q}+m_{p} / \rho_{p}+m_{r} / \rho_{r}} .
\end{aligned}
$$

If it was then assumed that the ratio of coarse aggregate was $R_{1}$, the barite sand substitution ratio was $R_{2}$. Substitution of $m_{r}=0.01 m$ into (10) gives

$$
\begin{aligned}
& \rho \\
& =\frac{1-n}{R_{1} R_{2} / \rho_{b}+R_{1}\left(1-R_{2}\right) / \rho_{q}+\left(1-R_{1}\right) / \rho_{p}+0.01 / \rho_{r}} .
\end{aligned}
$$

When the coarse aggregate was composed of quartz sand alone, $R_{2}=0$ and (11) was transformed to

$$
\begin{aligned}
\rho & =\frac{1-n}{R_{1} / \rho_{q}+\left(1-R_{1}\right) / \rho_{p}+0.01 / \rho_{r}} \\
& =\frac{\rho_{q} \rho_{p}(1-n)}{R_{1}\left(\rho_{p}-\rho_{q}\right)+\rho_{q}+\left(0.01 / \rho_{r}\right) \rho_{q} \rho_{p}} .
\end{aligned}
$$

According to Table $1, \rho_{q}<\rho_{p}$ and then it could be deduced that the bulk density of the equivalent material decreased with increasing coarse aggregate content, which agreed with the experimental evidence.

When the coarse aggregate was composed of barite sand alone, in other words, $R_{2}=100 \%$, (11) could be rewritten as

$$
\begin{aligned}
\rho & =\frac{1-n}{R_{1} / \rho_{b}+\left(1-R_{1}\right) / \rho_{p}+0.01 / \rho_{r}} \\
& =\frac{\rho_{b} \rho_{p}(1-n)}{R_{1}\left(\rho_{p}-\rho_{b}\right)+\rho_{b}+\left(0.01 / \rho_{r}\right) \rho_{b} \rho_{p}} .
\end{aligned}
$$


According to Table $1, \rho_{b}>\rho_{p}$ and then it could be deduced that the bulk density increased with increasing coarse aggregate content, which agreed with the experimental evidence.

When the coarse aggregate was composed of a mixture of barite sand and quartz sand, the bulk density changes were complicated and determined by the intercoupling of the three components. When the bulk density of the mixed coarse aggregate was lower than that of the barite powder, the bulk density tended to decrease with increasing coarse aggregate content. When the bulk density of the mixed coarse aggregate was similar to that of the barite powder, the bulk density variation was unrelated to the coarse aggregate content. The bulk density of the mixture also played an important role; for example, when the bulk density of the mixed coarse aggregate was similar to that of the barite powder, mixes with a better grading curve, and a lower porosity, had a higher bulk density (green line, Figure 7).

More test results indicate that, using barite sand and barite powder with higher bulk density (made by high-quality ore), the bulk density of equivalent material can be adjusted among larger range. The bulk density variation range of equivalent material can be as small as $2.0 \mathrm{~g} / \mathrm{cm}^{3}$ and as large as $2.8 \mathrm{~g} / \mathrm{cm}^{3}$, which covers the bulk density range of common rocks.

4.2. The Adjustment Method for Bulk Density. Since the test results revealed a very good linearity in the relationship between the barite sand substitution ratio and the bulk density, an adjustment method for bulk density of equivalent material is proposed as follows:

(1) Prepare the equivalent material by quartz sand and obtain the physical and mechanical parameters.

(2) Choose the needed material proportion according to similarity criterion (do not consider the bulk density here), and denote the bulk density by $\gamma_{1}$.

(3) Substitute barite sand for quartz sand completely, and denote the bulk density by $\gamma_{2}$.

(4) Assume that the preferred bulk density is $\gamma$, and then the barite sand substitution ratio $r$ can be determined by

$$
r=\frac{\gamma-\gamma_{1}}{\gamma_{2}-\gamma_{1}}
$$

Substituting barite sand for quartz sand according to the determined substitution ratio, equivalent material with the preferred bulk density and mechanical parameters can be prepared. The proposed method can be applied to equivalent material with coarse aggregate content less than $50 \%$.

\subsection{The Unexpected Increase in Index Mechanical Properties.} The test results verified the idea that the substitution of quartz sand with barite sand had no apparent influence on the key mechanical properties of the proposed equivalent material. However, when the barite sand content was high, the UCS and elastic modulus increased with increasing barite sand content.
In group M3, mechanical index properties underwent no apparent increase until the relative barite sand content reached $40 \%$. In group $\mathrm{M} 4$, the threshold relative barite sand content was between 30\% (M4-3, 60\% × 50\% = 30\%) and $40 \%(\mathrm{M} 4-4,80 \% \times 50 \%=40 \%)$. The test results implied that the threshold decreased as the coarse aggregate content increased.

To describe the frictional properties of the coarse aggregate, its angle of repose was measured (for both barite sand and quartz sand) and found to be 38.0 degrees and 36.5 degrees, respectively. The results indicated that the friction coefficient between barite sand particles was slightly larger than that between quartz sand particles.

When the coarse aggregate content was relatively low, the sand particles were separated by the fine aggregate particles and were unlikely to make direct contact. In this case, the moderate variations in the properties of the coarse aggregate resulted in no apparent influence on the mechanical properties of the equivalent material, just as the test results from groups M1 to M3 demonstrated. However, when the coarse aggregate content increased, the probability of direct interfacial friction between sand particles increased which tended to enhance the mechanical properties. In group M4, the mass ratio of the aggregate was $50 \%$, which was larger than that in the first three groups. When the barite sand substitution ratio exceeded $60 \%$, the UCS and elasticity increased slightly.

\section{Conclusions}

The analysis and comparisons made in this investigation confirmed the idea that the substitution of quartz sand by barite sand had little influence on the mechanical properties of the equivalent material in most cases (and particularly when the coarse aggregate content was less than 50\%). The results also showed that the bulk density of the equivalent material increased linearly with an increasing barite sand substitution ratio across all four groups. Thus the desired material, with the preferred bulk density, can be designed and its UCS and elastic modulus are predicted before testing. Further analysis revealed that, for higher coarse aggregate contents and a higher barite sand substitution ratio, the bearing capacity of the equivalent material tended to increase therewith: trial and error methods were still needed in these cases.

Although the test results did not verify the concept in its entirety, they did help to reduce the trial mix work significantly in most cases. Besides, the test results have already been used as guidance in the preparation of a resin-based equivalent material with a different target bulk density and mechanical properties: this will be further utilised to build similar models simulating tunnelling in deep-buried rock masses.

\section{Notations}

$\alpha$ : Parametric scale factor

$\sigma:$ Stress $(\mathrm{MPa})$

L: Length (m) 


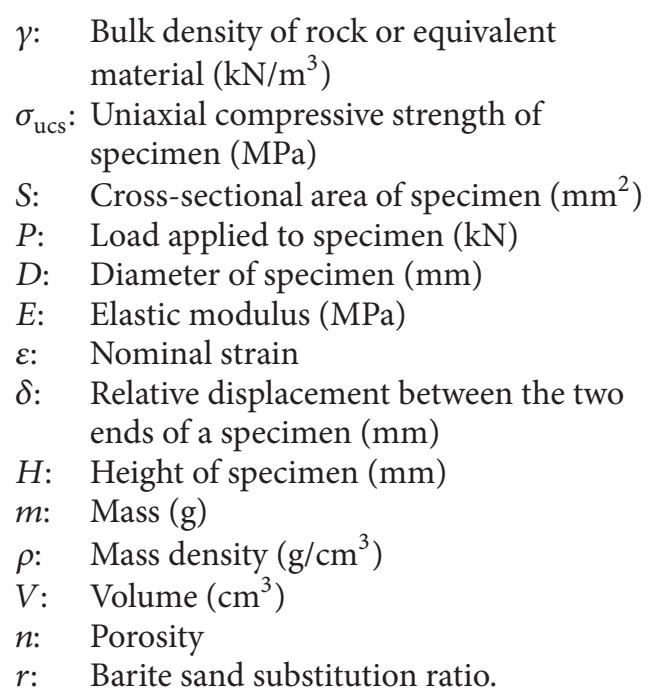

\section{Conflict of Interests}

The authors declare that there is no conflict of interests regarding the publication of this paper.

\section{Acknowledgments}

The authors would like to acknowledge the financial support from the National Key Basic Research Program of China (Grant 2013CB036005) and the National Natural Science Funds of China (Grants 51304219 and 51309234). The authors also thank the financial support of the Open Projects of State Key Laboratory of Coal Resources and Safe Mining, CUMT (Grant 14KF02), and China Postdoctoral Science Foundation (Grant 2015T81074).

\section{References}

[1] P. X. Fan, M. Y. Wang, K. F. Jiang, and Z. Z. Li, “Time-dependent problems in geo-mechanical model tests," Chinese Journal of Rock Mechanics and Engineering, vol. 33, no. 9, pp. 1843-1851, 2014.

[2] S. Chen, H. Wang, J. Zhang, H. Xing, and H. Wang, "Experimental study on low-strength similar-material proportioning and properties for coal mining," Advances in Materials Science and Engineering, vol. 2015, Article ID 696501, 6 pages, 2015.

[3] Q.-Y. Zhang, X.-G. Chen, B. Lin, D.-J. Liu, and N. Zhang, "Development and application of high-geostress true 3D loading geomechanics model test system," Chinese Journal of Geotechnical Engineering, vol. 32, no. 10, pp. 1588-1593, 2010.

[4] S.-C. Li, Q. Wang, W.-T. Li et al., "Research on application of flexible uniform pressure loading device to model test," Rock and Soil Mechanics, vol. 35, no. 1, pp. 61-66, 2014.

[5] P. X. Fan, M. Y. Wang, and X. Fang, "The boundary conditions of model test for deep-buried engineering and its simulation methods," Journal of Mining and Safety Engineering, vol. 33, no. $1,2016$.

[6] Z. K. Li, A. M. Wang, K. Z. Wang, Y. Liao, and S. Y. Fu, "Study and application of inverse controlling technology for $3 \mathrm{~d}$ geomechanical model construction of underground engineering," Chinese Journal of Rock Mechanics and Engineering, vol. 28, no. 9, pp. 1729-1734, 2009.
[7] W. S. Zhu, Q. B. Zhang, H. H. Zhu et al., "Large-scale geomechanical model testing of an underground cavern group in a true three-dimensional (3-D) stress state," Canadian Geotechnical Journal, vol. 47, no. 9, pp. 935-946, 2010.

[8] Y. R. Liu, F. H. Guan, Q. Yang, R. Q. Yang, and W. Y. Zhou, "Geomechanical model test for stability analysis of high arch dam based on small blocks masonry technique," International Journal of Rock Mechanics and Mining Sciences, vol. 61, pp. 231243, 2013.

[9] Y. Chen, L. Zhang, B. Yang, J. Dong, and J. Chen, "Geomechanical model test on dam stability and application to Jinping High arch dam," International Journal of Rock Mechanics and Mining Sciences, vol. 76, pp. 1-9, 2015.

[10] S. C. Li, Q. Wang, H. T. Wang et al., "Model test study on surrounding rock deformation and failure mechanisms of deep roadways with thick top coal," Tunnelling and Underground Space Technology, vol. 47, pp. 52-63, 2015.

[11] X.-G. Chen, Q.-Y. Zhang, Y. Wang, S.-C. Li, and H.-P. Wang, "In situ observation and model test on zonal disintegration in deep tunnels," Journal of Testing and Evaluation, vol. 41, no. 6, pp. 990-1000, 2013.

[12] E. Fumagalli, Statical and Geomechanical Models, Springer, New York, NY, USA, 1973.

[13] F. P. Glushikhin, G. N. Kutsnetsov, M. F. Shklyarsky et al., Modeling in Geo-Mechanics, Nedra, Moscow, Russia, 1991.

[14] Z. Li, D. Lu, H. Nakayama, H. Hosomi, and S. Jiansheng, "Development and application of new technology for 3D geomechanics model test of large underground houses," Chinese Journal of Rock Mechanics and Engineering, vol. 22, no. 9, pp. 1430-1436, 2003.

[15] H. P. Wang, S. C. Li, Q. B. Zhang, Y. Li, and X. H. Guo, "Development of a new geomechanical similar material," Chinese Journal of Rock Mechanics and Engineering, vol. 25, no. 9, pp. 1842-1847, 2006 (Chinese).

[16] Q.-Y. Zhang, S.-C. Li, X.-H. Guo, Y. Li, and H.-P. Wang, "Research and development of new typed cementitious geotechnical similar material for iron crystal sand and its application," Rock and Soil Mechanics, vol. 29, no. 8, pp. 2126-2130, 2008.

[17] W. Z. Ren, C. M. Guo, Z. Q. Peng, and Y. G. Wang, "Model experimental research on deformation and subsidence characteristics of ground and wall rock due to mining under thick overlying terrane," International Journal of Rock Mechanics and Mining Sciences, vol. 47, no. 4, pp. 614-624, 2010.

[18] W. S. Zhu, Y. Li, S. C. Li, S. G. Wang, and Q. B. Zhang, "Quasithree-dimensional physical model tests on a cavern complex under high in-situ stresses," International Journal of Rock Mechanics and Mining Sciences, vol. 48, no. 2, pp. 199-209, 2011. 

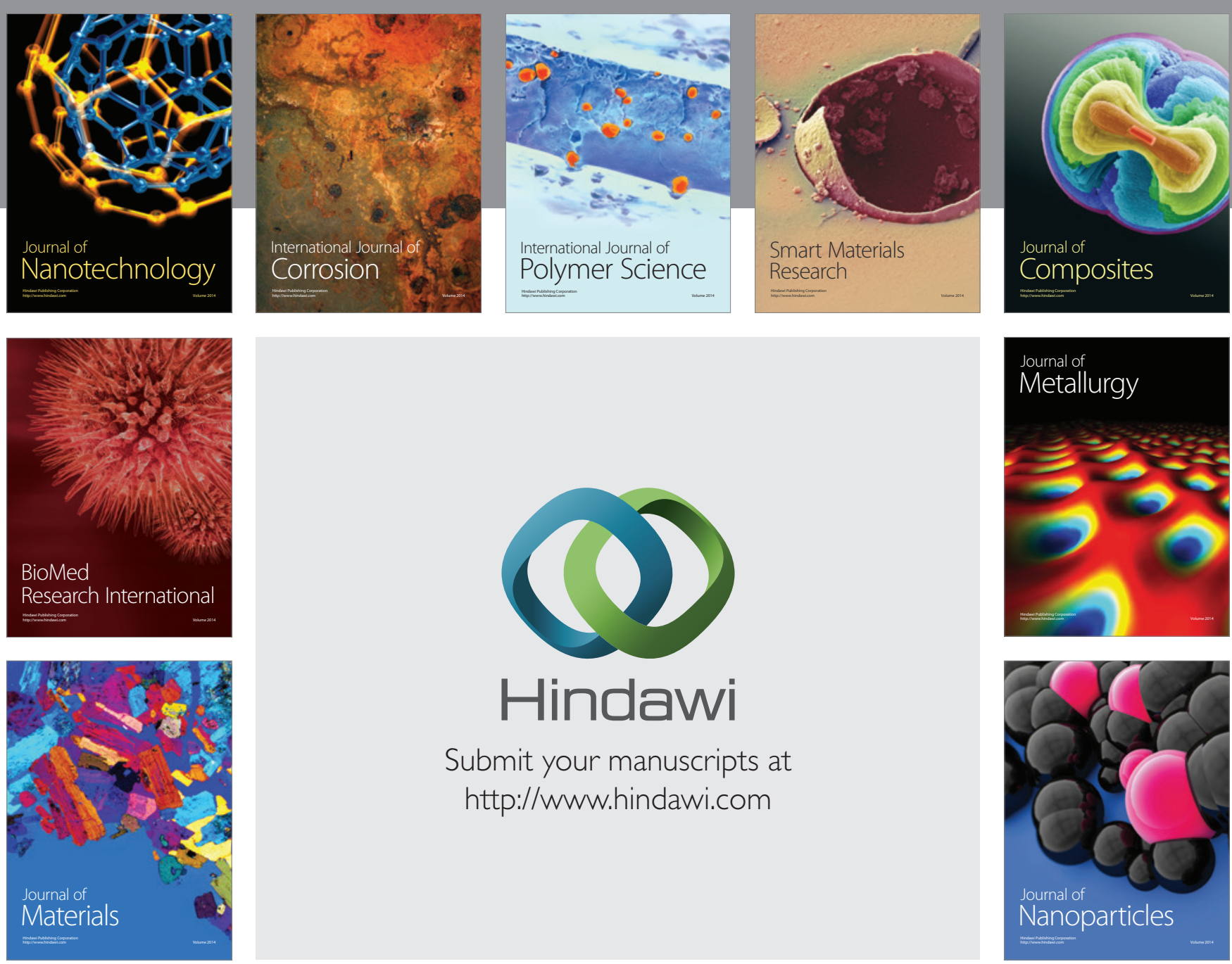

Submit your manuscripts at http://www.hindawi.com
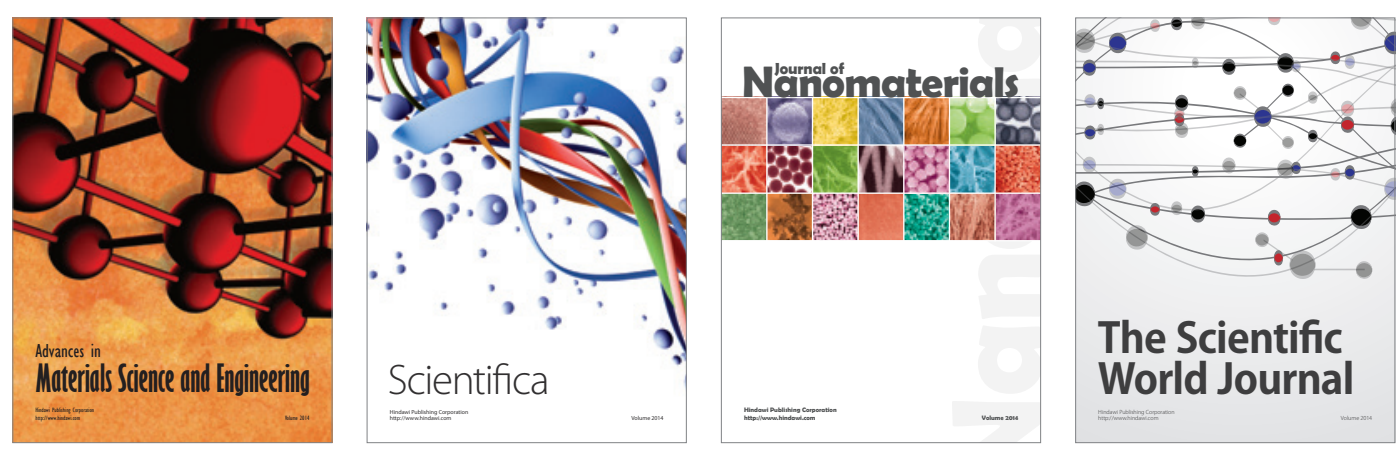

\section{The Scientific World Journal}
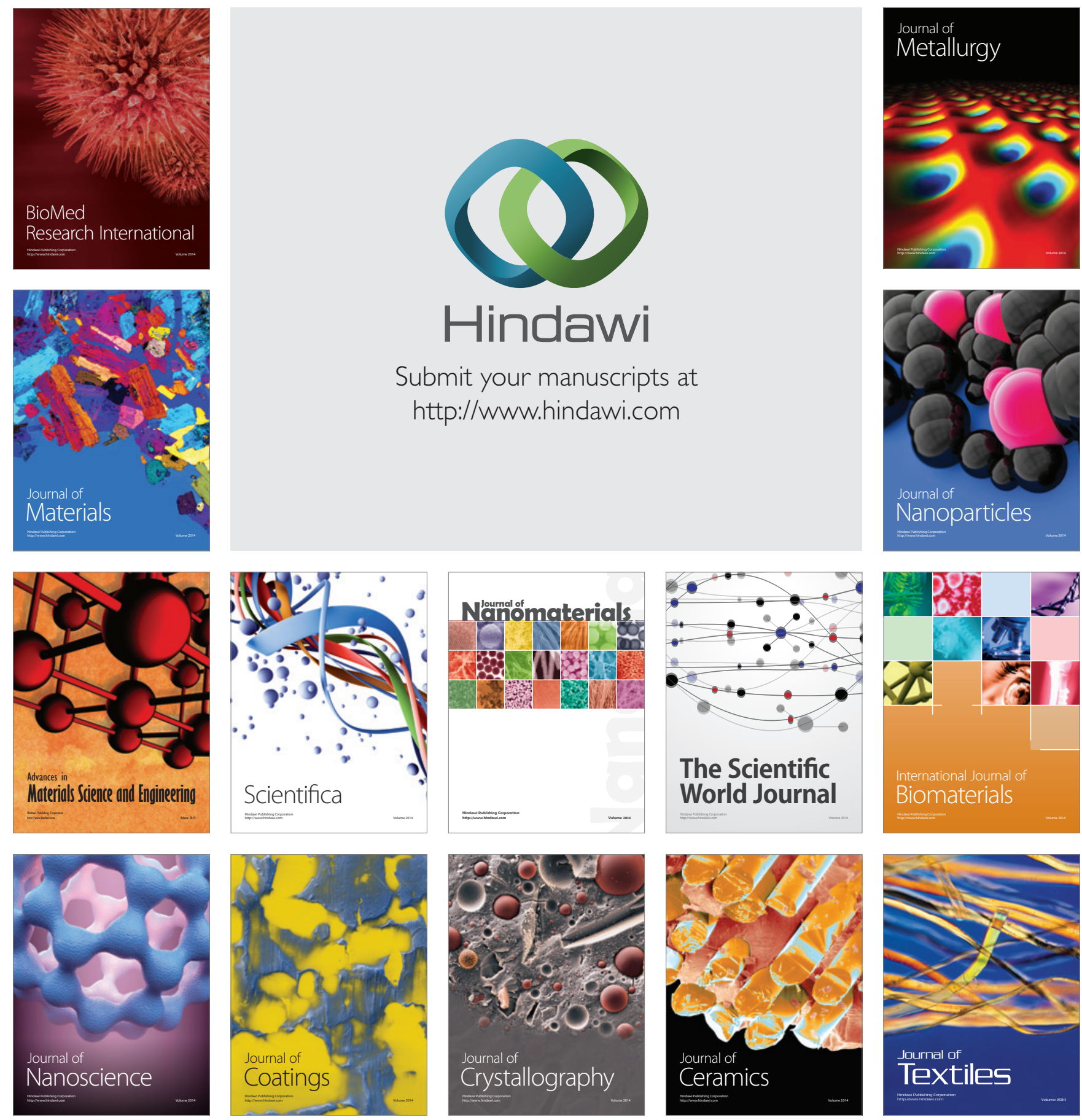